\title{
GOBERNABILLAD ASIMÉTRICA, TRABAJO DECENTE Y DERECHOS DE LOS MIGRANTES
}

BRANKA LIKIC-BRBORIC*

CARL-ULRIK SCHIERUP*

\section{Resumen}

El régimen surgido en el mercado laboral mundial de las últimas tres décadas se ha caracterizado por precarias condiciones de trabajo que afectan sobre todo a los inmigrantes irregulares. A través de una serie de movimientos sociales y políticos a todos los niveles, se han generado estrategias y discursos de cuestionamiento que enfatizan la importancia de los derechos universales y colectivos. En relación con estas iniciativas, se abordan en este documento los temas de la rendición de cuentas y contingencias que se refieren a la instrumentación de los derechos de los migrantes y del Programa de Trabajo Decente (DWA) de la Organización Internacional del Trabajo (OIT). Se argumenta que la creación de un modelo viable para la institucionalización de las normas laborales no puede dejarse en manos del actual y asimétrico régimen de gobernabilidad mundial. Se destaca el papel fundamental de las organizaciones sindicales, así como otras organizaciones de la sociedad civil (OSC), en el establecimiento de un enfoque basado en los derechos migratorios, las normas laborales y el desarrollo dentro del contexto de una globalización justa.

Palabras clave: gobernabilidad mundial, programa de trabajo decente, derechos de los migrantes, derechos humanos, fuerza de trabajo

* REMESO, Universidad de Linköping 


\begin{abstract}
The global labour market regime that has emerged during the past three decades is characterized by precarious working conditions, mostly affecting illegal migrants. A range of social and political movements on all levels has generated strategies and discourses of contestation that emphasize the importance of universal and collective rights. In connection with these initiatives, this article addresses the issues of accountability and contingencies for the implementation of migrants' rights and the human rights included in the ILO's decent work agenda (DWA). It is argued that the creation of a workable model for the institutionalisation of labour standards cannot be left to the currently asymmetric global governance regime. Emphasis is placed on the key role of trade-union confederations and other civil society organizations (CSOs) in establishing an approach based on migratory rights, labour standards and the development of fair globalisation.
\end{abstract}

Keywords: global governance, decent work agenda, migrants' rights, human rights, labour force 


\section{INTRODUCCIÓN ${ }^{1}$}

$\mathrm{H}$ asta ahora, la globalización en curso se ha encauzado hacia la “acumulación por desposesión" (Harvey, 2005), lo que implica una notable reducción de los derechos laborales (Hertel, 2009).

Las políticas de desregulación, reestructuración corporativa y ajuste estructural han privado a los trabajadores de la protección y poder de negociación anteriormente proporcionados por la regulación de los mercados y las políticas redistributivas. La contingente "remercantilización" del trabajo (Papadopoulos, 2005; Slavnic, 2010) ha forzado, a cada vez más categorías de trabajadores, a vender su trabajo al precio ofrecido por el mercado. En las últimas tres décadas, el nuevo régimen laboral mundial se ha caracterizado por una creciente informalidad y precarización. Al igual que la "remercantilización" del trabajo, los nuevos flujos migratorios mundiales, a menudo irregulares, juegan un papel importante en dicha configuración mercantil (Bauder, 2006). En general, los trabajadores se encuentran ahora despojados de sus principales derechos humanos, laborales y migratorios (Overbeek, 2003).

Esta situación también puede describirse a partir del enorme impulso al "neoliberalismo disciplinario" y el "nuevo constitucionalismo" para reafirmar los derechos de propiedad privada (Gill, 2005). Se trata de un sustancial cambio normativo: donde antes se daba prioridad a un paquete integrado por derechos sociales, laborales y humanos, ahora tienen primacía los derechos de propiedad privada, y los derechos humanos se interpretan en términos de mercado y delibertades individuales (Harvey 2005). La economía política se caracteriza por la desigualdad exacerbada, al tiempo que se alimenta un "metabolismo económico" global (Luxemburgo, 1951; 63:444) marcado por la inserción asimétrica de países subdesarrollados y de países ex socialistas de Europa central y del Este en la actual financiarización de la economía mundial (Dore, 2008).

1. Artículo inicialmente presentado en la Acción Global de los Pueblos (AGP) sobre Migración, Desarrollo y Derechos Humanos, Ciudad de México, 2-5 de noviembre de 2010. 
Bajo tales condiciones, los Estados nacionales, organismos socioeconómicos mundiales y regionales, así como sindicatos y otras organizaciones de la sociedad civil, afrontan grandes desafíos. Pese a la plétora de declaraciones que ofrecen el compromiso de respetar los derechos humanos y las convenciones existentes, la práctica deja mucho que desear. Las deficiencias se hacen evidentes, sobre todo, en el caso de los migrantes laborales irregulares y solicitantes de asilo, quienes están desprovistos del "derecho a tener derechos" (Arendt, 1958; Krause, 2008; Schierup, Hansen y Castles, 2006) y expuestos a algunas de las peores formas de precariedad laboral y a pésimas condiciones de vida. La informalidad de la economía, y su nexo con una persistente ausencia de derechos para los migrantes irregulares, es uno de los problemas sociales contemporáneos más exigentes; se requiere prestar atención a los reclamos cosmopolitas (Soysal, 1994; Munck, 2007) que involucran el reconocimiento de los derechos de los no ciudadanos por los Estados nacionales.

La creciente fuerza de dicha "moral cosmopolita" comprende un "movimiento de oposición polanyiano"2 (Polanyi, 2001 [1944]) contra el avance desenfrenado de una economía de mercado sin regulaciones (Piore, 2009). Sin embargo, aunque el polifacético movimiento de oposición (countermovement) actual se asemeja a las conmociones sociales surgidas a partir de la depresión y la gran crisis económica y social de la década de 1930, Piore arguye que no hay que llevar esta comparación demasiado lejos: aunque las "teorías que guiaron la desregulación y la globalización en las décadas finales del siglo XX son descendientes directas de la filosofía de laissez faire que guió la globalización hace un siglo" (2009:162), las políticas sociales que surgieron a partir de la gran depresión de los treinta han sido ampliamente desacreditadas. En este contexto, la oposición de

2. En La gran transformación, escrito a raíz de la profunda crisis económica, política y social de la década de 1930, el historiador económico Karl Polanyi (2001 [1944]) argumentó que la estabilidad social y, con ella, la creación de un entorno favorable para la inversión a largo plazo y el desarrollo económico sustentable, han dependido, a través de la historia del capitalismo, de un "doble movimiento"; esto implica un precario equilibrio entre "dos principios organizativos en la sociedad": el principio del liberalismo económico, encaminado a la creación de un mercado autorregulado, y el principio de protección social, integrado a un movimiento de oposición destinado a la conservación del hombre y naturaleza, así como de la organización productiva. 
nuestros tiempos parece conformar muchas luchas sociales que difícilmente se hilvanan en una teoría o programa coherente.

Aun así, existe una gama de movimientos sociales y políticos a nivel transnacional, nacional y regional que ha generado estrategias y discursos que enfatizan la importancia de los derechos universales y colectivos. En estos discursos se transmite una idea positiva de libertad y justicia relacionada con la reafirmación de los derechos laborales como parte de los derechos ciudadanos, así como de los derechos de los migrantes y los derechos humanos en general (Munck, 2007; Gentile y Tarrow, 2009). Al igual que Jones (2010), argumentamos acercad de la necesidad de una "visión liberal completa" y una concepción más amplia de los derechos humanos. En este contexto, los derechos humanos son universales, indivisibles y entrañan valores igualitarios, tal como está expresado en la Declaración Universal de Derechos Humanos (1948), el Pacto Internacional de Derechos Civiles y Políticos (1966) y el Pacto Internacional de Derechos Económicos, Sociales y Culturales (1966). En esta perspectiva, los derechos humanos son también reclamos morales "basados en intereses, generadores de instituciones", que dan lugar al terreno normativo necesario para evaluar instituciones existentes o cambios institucionales a partir de nociones de humanidad compartida y justicia social (Jones, 2010:118). Aquí adoptamos una postura crítica con respecto a las concepciones más "ortodoxas" y restringidas de los derechos humanos, las cuales definimos como "interpretaciones minimalistas" que simplemente enumeran los derechos sin abordar asuntos cruciales como la justicia social y la igualdad. Una interpretación más amplia y ambiciosa justifica la inclusión de la justicia social global en los derechos humanos, es decir, los derechos sociales transnacionales y la ciudadanía social (p.ej., Faist, 2009).

Este el punto de partida del presente artículo. Nos hemos propuesto exponer una amplia, inclusiva y emergente conceptualización de un régimen de gobernabilidad mundial con múltiples niveles. Examinaremos someramente sus principales actores, discursos y prácticas, a fin de analizar críticamente la composición de los discursos en derechos humanos y laborales, así como las contingencias relacionadas con su institucionalización, instrumentación y la promoción de la justicia social global. 
Argumentamos que la exploración crítica de las fortalezas y debilidades de las actuales estrategias y prácticas asociadas a la promoción de un régimen basado en los derechos migratorios y laborales es de primordial importancia para una revisión del nexo entre migración y desarrollo en un modelo alternativo de desarrollo.

Esta cuestión debe abordarse desde dos grandes perspectivas críticas. La primera, de acuerdo con Piore (2009), es la necesidad de hacer un escrutinio crítico sobre los beneficios de un marco de acción formal $\mathrm{y}$, aparentemente, universalista referente a diversas condiciones económicas, sociales, políticas y culturales, y a voces particulares y discursos políticos de gobiernos nacionales, movimientos sociales, luchas locales, etcétera. La otra perspectiva, la que nos interesa, se centra en la auténtica rendición de cuentas de un régimen de gobernabilidad global emergente y en la coherencia de su discurso normativo, así como en la codificación, institucionalización, modos de instrumentación y sanciones.

Es necesario considerar que los actuales movimientos de la sociedad civil están enfrentados a un modelo de gobernabilidad global caracterizado por relaciones asimétricas de poder que otorgan preferencia unilateral a los intereses de las grandes transnacionales y el capital financiero; que los discursos de justicia social se encuentran inevitablemente sujetos a la primacía del "crecimiento económico", y que, por lo mismo, no hay sanciones reales si los marcos jurídicos son infringidos ni auténticas políticas y prácticas de instrumentación. ¿Podemos, acaso, discernir un contexto más complejo donde las luchas y la política de actores externos - y aquí nos enfocamos en los sindicatos y otras organizaciones de la sociedad civil- puedan entretejerse con las divisiones internas en el seno de las organizaciones de la gobernabilidad global dominante e interactuar efectivamente con ellas, promoviendo una actitud realmente positiva y multilateral en términos de políticas sociales y el establecimiento de normas laborales como objetivos políticos (relativamente) autónomos y prácticos? ? $^{3}$ as preguntas principales que nos conciernen son quién gobierna; quién establece la agenda; quiénes son los responsables; para qué y ante quién son responsables; quién actúa; de quién son las acciones que cumplen un papel efectivo.

3. Como en el caso del desarrollo del BM, examinado críticamente por Vetterlein (2007). 
En este sentido, destacamos el concepto de responsabilidad inclusiva propuesto por Lafont (2010), quien distingue entre soberanía democrática y responsabilidad democrática. Mientras que la primera implica la participación de todos los líderes en la formulación de las políticas, la segunda exige que los representantes se hagan responsables ante "todos aquellos sujetos a sus decisiones" (Lafont, 2010:195). Así que la cuestión de la responsabilidad inclusiva, aun ante los no ciudadanos que carecen de representación política, puede traducirse en una cuestión relacionada con mecanismos y herramientas capaces de garantizar la rendición de cuentas de cualquier líder.

El concepto de la rendición de cuentas, afirma Lafont, puede también utilizarse para abordar el evidente fracaso de la actual visión sobre los derechos humanos, centrada en el Estado (p.ej., Beitz, 2009), y adjudicar responsabilidad a actores no estatales - las empresas transnacionales, organizaciones multilaterales como la Organización Mundial de Comercio (OMC), el Banco Mundial (BM) y el Fondo Monetario Internacional (FMI) - en lo que se refiere al respeto y protección de los derechos humanos. Al diferenciar la obligación de "respetar, proteger y cumplir" los derechos humanos, los Estados se convierten en responsables de su protección y cumplimiento. Sin embargo, la "obligación universal" de respetar los derechos humanos debe compartirse entre actores estatales y no estatales (Lafont, 2010:203). Esta obligación, o responsabilidad compartida, es de particular importancia en el caso de los devastadores efectos que ha tenido en los derechos sociales y humanos la imposición de políticas neoliberales de desarrollo, especialmente en los países subdesarrollados. Dada la actual coyuntura y la reafirmación de un consenso transnacional que promueve medidas de austeridad como la principal respuesta política a la reciente crisis financiera, es de especial importancia la obligación que tienen los líderes globales poderosos de proteger los derechos humanos, laborales y migratorios. Por lo tanto, el punto general consiste en deliberar si es posible responsabilizar a los Estados poderosos y a los actores multilaterales para que respeten y promuevan los derechos humanos y laborales, y para que, además, se aseguren de su instrumentación. 
En la primera parte del artículo se presentan los contornos de un régimen emergente de gobernabilidad global en términos de sus dimensiones normativas, técnicas e institucionales. Acto seguido, examinamos las iniciativas para promover la justicia social global, en general, y los derechos laborales y de los migrantes, en particular. Para hacer una revisión del entendimiento neoliberal de la gestión de la migración y el desarrollo, en la tercera sección se explora el impacto del Programa de Trabajo Decente (DWA, por sus siglas en inglés) de la Organización Internacional del Trabajo (OIT) en la promoción de los derechos laborales y de los migrantes y se discuten las estrategias de diversos interesados, así como la importancia de sus discursos y prácticas. Hacemos hincapié en el papel esencial de las centrales sindicales mundiales y regionales, de otras organizaciones de la sociedad civil (OSC) y de la Acción Global de los Pueblos (AGP) para el establecimiento de un enfoque basado en los derechos migratorios, las normas laborales y el desarrollo en el contexto de una globalización justa. La creación de un modelo viable para la codificación, institucionalización y reconceptualización de los derechos humanos, en los términos de una política social global responsable que mantenga los derechos laborales y de los migrantes como pilares esenciales, no puede dejarse en manos del actual y asimétrico régimen de gobernabilidad mundial ni de los gobiernos nacionales o regionales interesados, como aquéllos que componen la Unión Europea (UE) o el Tratado de Libre Comercio de América del Norte (TLCAN). Estos cambios no serán posibles si no lo impulsa y respalda un heterogéneo movimiento social de oposición a la globalización neoliberal.

Aclaramos, por último, que este artículo toma una perspectiva primordialmente norteña y transatlántica, con especial atención a la continua degradación del modelo social europeo y su pérdida de prominencia como un modelo potencial para obtener justicia social a nivel global; sin embargo, subrayamos que la manera de avanzar en el desarrollo de un enfoque crítico múltiple verdaderamente global requiere de la inclusión de otras perspectivas regionales y centros de investigación transfronterizos, como argumenta, por ejemplo, Faist (2009:29). 


\section{RÉGIMEN EMERGENTE DE GOBERNABILIDAD GLOBAL: NUEVOS PARADIGMAS DE DESARROLLO Y NECESIDAD DE UNA RESPONSABILIDAD INCLUSIVA}

La gestión económica y sociocultural de la globalización ha implicado un cambio de gobierno a gobernabilidad en términos de respuestas institucionales generales y nacionales con consecuencias políticas en todo el mundo.

La gobernabilidad global se ha definido como "el conjunto de procesos normativos, sociales, jurídicos, institucionales y de otra índole que conforman y, en algunos casos, regulan y controlan la interacción dialéctica de la globalización y la fragmentación" (Clarke y Edwards, 2004:6). Clarke identifica tres niveles interconectados de gobernabilidad global: normativo, técnico (científico y social) e institucional. Subraya la importancia de legislar y codificar instancias normativas. La gobernabilidad normativa se entiende como un conjunto de ideas y principios éticos que conforman la visión de un régimen internacional, generan valores compartidos y estimulan la participación de los actores. La dimensión técnica de la gobernabilidad consta de mecanismos científicos y sociales y de acuerdos que promueven soluciones multilaterales y transnacionales a problemas y desafíos globales. Se puede decir que la dimensión institucional, que implica la participación de las instituciones multilaterales existentes, los Estados y las redes de políticas públicas, ha evolucionado hacia "un sistema más complejo en el que una diversidad de actores -Estados, ciudadanos, organizaciones internacionales, empresas y organizaciones no gubernamentales (ONG), entre otrosinteractúan en un sistema de varios niveles conformado por una diversidad de normas y disposiciones institucionales" (Clarke, 2004:262). No cabe duda de que el sistema de gobernabilidad mundial y su programa han sido fundamentalmente diseñados por los países más poderosos y económicamente avanzados, la Organización para la Cooperación y el Desarrollo Económico (OCDE), la organización de los países más desarrollados liderados por el G7 -y claramente dominada por Estados Unidos- y las empresas transnacionales. Este punto es de primordial importancia para la comprensión de los procesos de legalización basa- 
dos en diversas normas mundiales, que van de lo flexible a lo categórico, y se evalúan en términos de niveles de obligación legal, precisión y la delegación de instancias normativas.

Los principales actores de la gobernabilidad mundial han estado principal y consistentemente a cargo del proceso de globalización, y lo han enfilado hacia la creación de un régimen comercial liberal y un sistema financiero y monetario consagrado a la fundación de la OMC después de la Ronda Uruguay. La gobernabilidad mundial se ha reorganizado en torno a los procesos de negociación relacionados con el establecimiento del régimen de comercio global actual. Las instituciones financieras internacionales (IFI) de Bretton Woods - el BM y el FMIhan jugado un papel decisivo en la imposición del modelo neoliberal y la promoción del libre movimiento del capital. Con el firme apoyo de Estados Unidos y las economías más avanzadas, las IFI también han adquirido un rango exclusivo separado del resto de la arquitectura organizacional de la ONU; tienen un mandato claro y los recursos necesarios para promover un tipo de gobernabilidad económica mundial jerárquica aislada de agravios democráticos. A pesar de la adopción de una visión más afirmativa en términos de política social, relacionada con un cambio en su perspectiva del desarrollo posterior a su radical postura economicista durante la década de 1980 (p.ej., Vetterlein, 2007), el BM ha apoyado el Consenso de Washington de manera persistente, instrumentando reformas de política social "hacia abajo" y leyes laborales flexibles, independientemente del creciente descontento con su falta de democracia y compromiso social, así como su evidente fracaso para generar empleo y desarrollo económico.

Sin embargo, en el cambio de milenio, cada vez más está en duda el "paradigma Bretton Woods" y su optimismo sobre la erradicación de la pobreza a través de la inclusión de los países subdesarrollados en un régimen de comercio internacional impulsado por la OMC y el Acuerdo General sobre Aranceles Aduaneros y Comercio (GATT, por sus siglas en inglés) (Thérien, 2005). A través de varios fondos, comisiones y organismos coordinados por el Consejo Económico y Social (ECOSOC), se ha puesto en marcha un paradigma alternativo centrado en la Organización de las Naciones Unidas (ONU) (Thérien, 2005) y basado en 
un entendimiento distinto del nexo entre la liberalización global y la pobreza, la desigualdad, el deterioro de las condiciones sociales y los derechos humanos y laborales. Esto incluye el Programa de Desarrollo de las Naciones Unidas (PNUD), la OIT, el Fondo de las Naciones Unidas para la Infancia (UNICEF) y la Oficina del Alto Comisionado para los Derechos Humanos (ACNUDH) en colaboración con la Organización Internacional para las Migraciones (OIM). Dentro de una serie de mandatos superpuestos para promover el desarrollo humano, los derechos laborales y la justicia social, estos organismos multilaterales, han elaborado, en el curso de la década de 1990, un marco teórico y político integral para promover los aspectos sociales de la globalización. El paradigma de desarrollo y globalización alternativo de la ONU ya ha sido considerado por los actores más poderosos - G20, Unión Europea (UE), BM y FMI-. La gobernabilidad global emergente, sin embargo, se caracteriza todavía por un dualismo asimétrico que refleja desigualdades normativas basadas en el neoliberalismo y la consecuente subordinación de la gobernabilidad global a la supremacía del libre comercio y la libre circulación de capital (véase cuadro 1.1).

CUADRO 1

Hacia la globalización (justa)

\begin{tabular}{|c|c|}
\hline Paradigma de la ONU & Paradigma Bretton Woods \\
\hline $\begin{array}{l}\text { - Comercio justo (fair trade): enfoque de políti- } \\
\text { cas integradas/ interacción entre políticas } \\
\text { macroeconómicas, comerciales, laborales y } \\
\text { sociales } \\
\text { - Regulación del mercado de capital global } \\
\text { - Inclusión de la DWA en los "Objetivos de de- } \\
\text { sarrollo del milenio" (ODM) y en la "Estrate- } \\
\text { gia para la reducción de la pobreza" } \\
\text { - Acuerdos comerciales bilaterales, regionales y } \\
\text { negociaciones de la OMC } \\
\text { - Piso socioeconómico global } \\
\text { - Normas migratorias justas: los derechos huma- } \\
\text { nos y de los trabajadores deben ser para todos, } \\
\text { incluyendo a los migrantes en situación irreg- } \\
\text { ular y a los trabajadores con empleo informal. }\end{array}$ & $\begin{array}{l}\text { - Comercio sin ayuda: libre comercio como } \\
\text { instrumento principal de desarrollo- } \\
\text { OMC } \\
\text { - Responsabilidad social corporative (RSC) } \\
\text { - Gestión de la migración } \\
\text { - Estrategia para la reducción de la pobreza } \\
\text { - Objetivos de desarrollo del milenio (ODM) } \\
\text { - Desvinculación de las cláusulas sociales de } \\
\text { la OIT de las consultas de la OMC (1996) }\end{array}$ \\
\hline
\end{tabular}

Fuente: Thérien (2005) 
Las profundas asimetrías actuales también se reflejan en las dimensiones técnicas e institucionales de la arquitectura de la gobernabilidad mundial y no han sido cuestionadas por la crisis financiera mundial, lo que resulta paradójico, especialmente si tenemos en cuenta su catastrófico impacto socioeconómico, la actual falta de legitimidad del modelo de desarrollo liderado por el mercado y la reafirmación de alternativas críticas que aseveran la importancia de las políticas sociales y los derechos laborales. Gill afirma que estamos atestiguando una serie de procesos que buscan atenuar y cooptar "las fuerzas democráticas a fin de evitar un segundo 'doble movimiento' Polanyiano"; es decir, un movimiento social de oposición compuesto que podría impulsar una "reordenación autoritaria" (2005:182). Aquellos discursos que enfatizan la justicia social, los derechos humanos y la importancia de establecer una agenda de trabajo decente han sido, sin duda, incluidos en los marcos normativos de la gobernabilidad global, pero se les ha subordinado a las exigencias del libre comercio y a las excluyentes prácticas institucionales dominantes; éstas han impulsado la financiarización de la economía mundial y las medidas de austeridad económica que no se han desafiado de manera efectiva ni han sido contrarrestadas en su estado actual. Esto refuerza un régimen de mercado laboral mundial emergente caracterizado por:

- La expansión del comercio transnacional, la inversión extranjera directa (IED), fusiones y adquisiciones y la configuración de cadenas de producción mundial asimétrica;

- Nuevas formas de "mercantilización” o "remercantilización” global del trabajo;

- Regímenes de migración global y regional que suponen una mayor polarización y segmentación de la fuerza de trabajo, dividida por complejas categorías de capacidad, origen étnico (o "raza") y género;

- Creciente informalidad del mercado laboral en economías avanzadas y en desarrollo;

- Creación de marcos regionales de seguridad y gestión migratoria que dan prioridad a las finanzas sobre los derechos humanos.

Para identificar los obstáculos y contingencias que conlleva un desafío acreditado al discurso dominante sobre migración y desarrollo, la 
siguiente sección examina la creación de un discurso alternativo de la globalización, un discurso que parece, al menos a primera vista, tener en cuenta la justicia social global y los derechos laborales y migratorios.

\section{JUSTICIA SOCIAL GLOBAL, TRABAJO DECENTE Y GLOBALIZACIÓN JUSTA}

El debate sobre las normas internacionales del trabajo elaborado y supervisado por la OIT ha desempeñado un papel importante en el desarrollo de un discurso alternativo sobre la globalización, especialmente en relación con el establecimiento de la OMC. Las discusiones de su potencial impacto se han centrado en la poca influencia de convenios y recomendaciones de la OIT, los cuales carecen de carácter obligatorio, así como en la necesidad de vincular acuerdos comerciales multilaterales como los del GATT, OMC y TLCAN a normas laborales estandarizadas con cláusulas sociales autorizadas (p.ej., Malmberg y David, 1998). A fin de corregir la repetida ausencia de cláusulas sociales en las negociaciones de la OMC y la exclusión de la OIT de dichas negociaciones, en junio de 2000, la Asamblea General de la ONU pidió a la OIT que formulara una estrategia integral de empleo global.

Ante la oportunidad de restaurar su autoridad en el marco de la gobernabilidad mundial, la OIT reafirmó su compromiso con la justicia social a través de la creación de una agenda de trabajo decente (DWA, por sus siglas en inglés), formulada por su director general, Juan Samovia, en el Informe de trabajo decente de 1999 (OIT, 1999). De acuerdo con el informe, el objetivo primordial de la OIT es "promover oportunidades para que mujeres y hombres puedan obtener un trabajo decente y productivo en condiciones de libertad, igualdad, seguridad y dignidad" (OIT, 1999). La DWA corroboró el principio básico de la Constitución de la OIT y representa una "desmercantilización" del trabajo, reafirmando la Declaración sobre Principios y Derechos Fundamentales en el Trabajo y su Seguimiento de 1998. También ha recurrido a un conjunto de previas declaraciones internacionales sobre derechos humanos, sociales, económicos y culturales. La Declaración afirma ocho convenios fundamentales que garantizan la libertad de asociación, el reconocimiento de la negociación colectiva, la eliminación del trabajo 
forzoso, la prohibición del trabajo infantil, la eliminación de la discriminación en el empleo y la ocupación, y el derecho a un salario. Estos derechos también están vinculados a la Declaración Universal de Derechos Humanos de 1948, el Pacto Internacional de Derechos Económicos, Sociales y Culturales de 1966 y la Declaración y Compromisos de la Cumbre Mundial sobre Desarrollo Social de 1995.

Por otra parte, el revitalizado papel de la OIT en la reafirmación y promoción de normas laborales también está ligado a otros objetivos más ambiciosos como la promoción del empleo, la seguridad y protección social y el diálogo social, además de estrategias para alcanzar estos objetivos y tomar en cuenta a todos los trabajadores, incluso aquéllos con empleo irregular y los que trabajan por cuenta propia o en el hogar. Además de estos objetivos y estrategias, la DWA va más allá de afirmar un piso social universal para la globalización económica, también cuestiona el enfoque convencional del desarrollo y crecimiento económico global y propone un enfoque integral para un desarrollo sustentable y políticas macroeconómicas que reconozcan los beneficios de reducir el "déficit de trabajo decente". En su informe de 2001, el director general afirma que el trabajo decente es accesible y viable, y que requiere coherencia a fin de abarcar sus objetivos económicos y sociales a la vez que reafirma su universalidad (OIT, 2001).

Para alcanzar estos objetivos, los expertos de la OIT han colaborado no sólo con sindicatos, empleadores y gobiernos, sino también con movimientos sociales mundiales y organizaciones no gubernamentales (ONG). Una serie de informes emitidos anualmente y numerosos documentos de debate se han centrado en diferentes facetas del empleo, la creciente pobreza y las condiciones de trabajo. Uno de los informes más importantes es $\mathcal{E}$ l trabajo decente y la economía informal (OIT, 2002). La preparación y aprobación del informe involucró agitados debates; de hecho, el principal marco para el debate y el informe fue presentado por Mujeres en Empleo Informal: Globalizando y Organizando (Women in Informal Employment: Globalizing and Organizing, [WIEGO]), una red mundial de investigación de políticas públicas dirigida por Martha Chen, profesora en la Kennedy School of Government de la Universidad de Harvard (Chen, Vanek y Carr, 2004). Entre otras organizaciones involucradas se encontraban la International 
Restructuring Education Network Europe (IRENE), el Global Labour Institute (GLI), la Confederación Internacional de Organizaciones Sindicales $\mathcal{L}$ ibres (CIOSL) y una docena de otras ONG, así como activistas que presentaron informes regionales y nacionales durante el proceso preparatorio. Los temas principales fueron los siguientes: quién habría de representar a los trabajadores en la economía informal y cómo se habría de habilitar la participación de ONG que ya trabajaban con trabajadores informales en la Conferencia Internacional del Trabajo (CIT), la reunión anual de los representantes de los Estados miembros en Ginebra. Los procedimientos de la OIT están basados en representaciones formales tripartitas, es decir, que la delegación de cada Estado miembro está conformada por dos delegados gubernamentales, un empleador y un delegado de los trabajadores y sus asesores. Dado que el empleador y el trabajador representan organizaciones nacionales formales, la participación de las ONG se aseguró con la enmienda adoptada en la sesión 90 del CIT durante la presentación del informe sobre la economía informal.

El informe señaló la creciente informalidad laboral, su complejidad y el hecho de que la mayor parte de los trabajos en países subdesarrollados y en transición se han generado en la economía informal y cuestionó el uso del término "sector informal" por ser demasiado estrecho. Se propuso un enfoque integral a la informalidad y se adoptó el término "economía informal" para denotar la heterogeneidad del fenómeno, que debe incluir relaciones de empleo informal y de negocios informales, así como a una diversidad de actores (trabajadores y empresas) que operan de manera informal; esto incluye trabajadores autónomos, vendedores ambulantes, boleros, trabajadores domésticos con sueldo, trabajadores domésticos sin sueldo, trabajadores en talleres de explotación laboral aunados a cadenas de producción, aquéllos a cargo de microempresas y sus familiares empleados. Según la OIT (2002:2-3), estos grupos de actores comparten la falta de reconocimiento legal y protección, así como una extrema vulnerabilidad; dependen de compromisos institucionales informales que generan su propia e idiosincrática economía política. ${ }^{4}$

4. Esta sección está basada en Likic-Brboric (2007). 
El amplio marco para este enfoque integral también se ha elaborado con base en la idea de que la economía informal sólo puede entenderse si se relaciona con la configuración de la economía formal y que el "déficit de trabajo decente" ha puesto seriamente en peligro las condiciones de trabajo decente en la economía formal a través de la creación de las presiones competitivas basadas en prácticas desleales. En consecuencia, la OIT definió su objetivo: "promover el trabajo decente en todo el universo continuo de la actividad económica, que abarca desde el sector informal hasta el sector formal, aplicando enfoques orientados al desarrollo, la reducción de la pobreza y la igualdad de género" (OIT, 2003:5).

La DWA es parte de una estrategia integral para eliminar las causas de la informalidad y consta de cuatro módulos: $a)$ generar oportunidades de empleo e ingresos; $b$ ) mejorar los derechos laborales; $c$ ) mejorar la protección social; y $d$ ) dar voz a la economía informal. Musiolek (2002) identifica toda una gama de instrumentos políticos para promover los objetivos de la DWA en el contexto de los países de Europa del Este Central y la Comunidad de Estados Independientes (CEI): ratificación e instrumentación de estándares laborales básicos y el derecho de sindicación, promoción del espíritu empresarial y la pequeña empresa, esquemas de movilidad y políticas activas de mercado laboral, incluyendo educación y desarrollo de habilidades, microfinanzas, esquemas de protección social, seguridad y salud ocupacional, e inclusión de las normas de trabajo en el trabajo informal de planificación urbana.

También hace hincapié en que la OIT, los sindicatos y las ONG tienen que involucrar a todos los actores nacionales e internacionales en el proceso del DWA. Además de la OIT, la Comisión y Parlamento de la UE, órganos regionales como el TLC y la Association of Southeast Asian Nations (ASEAN), las organizaciones de la ONU, empresas transnacionales, sindicatos internacionales y movimientos y redes sociales mundiales deben asumir la responsabilidad de su instrumentación. En el plano nacional, los actores deben incluir gobiernos centrales y locales, inspectores de trabajo, autoridades fiscales, empresarios, sindicatos y ONG, así como propietarios de empresas informales y sus empleados.

Para alcanzar estos objetivos estratégicos, y con el propósito general de reinventarse como principal foro para el diálogo sobre políticas 
sociales, la OIT lanzó otras varias iniciativas mundiales que han pasado a estructurar un discurso de justicia global y solidaridad basado en el concepto de trabajo decente, además de marcos normativos y cognitivos alternativos que apoyan políticas encaminadas a una reconfiguración discursiva del orden mundial. ${ }^{5}$

Al nivel más alto, la OIT estableció la Comisión Mundial sobre la Dimensión Social de la Globalización (WCSDG, por sus siglas en inglés), que produjo su informe final Por una globalización justa en 2004. El informe hace un balance sobre el impacto de la globalización y propone un marco inclusivo para una gobernabilidad mundial que equilibre las instituciones financieras y económicas mundiales, el capital libre y los flujos comerciales con un piso social universal, con los derechos humanos y laborales y con normas justas para el movimiento transfronterizo de personas (WCSDG, 2004). Dado que la migración es un fenómeno global cada vez más importante, otra iniciativa se centra en la construcción del Grupo Mundial sobre Migración (GMM), junto con la Organización Internacional para las Migraciones (OIM) y varias agencias e iniciativas complementarias de la ONU en el campo de la migración. El secretario general de la ONU también estableció la Comisión Mundial sobre las Migraciones Internacionales (CMMI), la cual presentó su informe en 2005 (GCIM, 2005). El informe examinó los problemas de la migración mundial, especialmente la creciente migración indocumentada, y reafirmó los mecanismos jurídicos existentes que deben enmarcar las políticas de migración.

\section{Una aproximación a la migración laboral internacional con derechos}

La OIT inició la elaboración de un marco multilateral no vinculante para una aproximación a la migración laboral con derechos y estableció un diálogo sobre migración en colaboración con organizaciones internacionales y multilaterales. Esto se justifica a partir del hecho de que la globalización ha sido acompañada, a nivel de configuración regional,

5. De acuerdo con Fairclough (1992), se trata de una lucha hegemónica gramsciana por una reconfiguración ideológica del orden político y su institucionalización. Ver LikicBrboric (2003). 
por la precariedad en países subdesarrollados y, cada vez más, en las economías desarrolladas. Se le designa de diversas formas: "non-standard jobs" en Canadá, "contingent work" en Estados Unidos o "trabajos precarios" en Europa Occidental (Waite, 2009).

Definimos trabajo precario como una diversidad de formas de empleo por debajo de los estándares normativos socialmente establecidos que resultan de una distribución desequilibrada de inseguridad y riesgos típicamente asociados al mercado de trabajo (Frade y Darmon, 2005:107). Según Woolfson y Likic-Brboric (2008), los migrantes son particularmente vulnerables a dichos riesgos, tanto a nivel espacial como de contrato, además de que se encuentran dislocados de las estructuras de protección social, expuestos al abuso. Lo que es más, los migrantes irregulares/indocumentados/clandestinos o "apátridas" (Arendt, 1958) y los solicitantes de asilo no reconocidos se encuentran en "una situación de falta de derechos radical" (Krause, 2008:344), sin acceso a representación o voz. Su situación podría ser designada como hiperprecaria y caracterizada por la superexplotación.

Teniendo en cuenta la supuesta importancia de la migración como una herramienta para la configuración de un mercado de trabajo equilibrado, el Marco Multilateral de la OIT para las Migraciones Laborales sirve no sólo para reforzar el DWA, sino que también subraya otros principios y directrices para la aplicación de un enfoque basado en los derechos de los migrantes. Las metas son:

asegurar la coherencia entre migración laboral, trabajo digno, empleo y otras políticas nacionales; formular e instrumentar políticas de migración laboral guiadas por normas laborales internacionales y otros instrumentos internacionales pertinentes, así como acuerdos multilaterales relativos a los trabajadores migrantes; abordar las vulnerabilidades específicas de ciertos grupos de trabajadores migrantes, incluidos aquellos en situación irregular, y asegurar que las políticas de migración laboral sean sensibles a cuestiones de género (OIT, 2010:209).

Este marco se refiere a una serie de convenios fundamentales de la OIT y sus recomendaciones, así como a instrumentos relativos a la migración y convenciones de la ONU, que se reúnen en el siguiente cuadro. 
CUADRO 2

Marco institucional de la oIT para migración con derechos

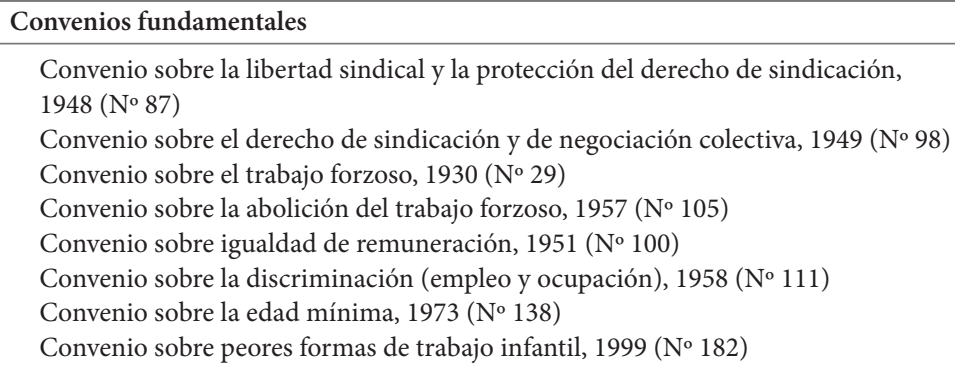

Convención internacional sobre la protección de los derechos de todos los trabajadores migratorios y de sus familiares, 1990

Fuente: (OIT, 2010:268-9) 
xSi bien el marco multilateral de la OIT para la migración es un documento imponente, sufre de la falta de carácter no vinculante que aqueja a la OIT y a otros instrumentos internacionales de derechos humanos y laborales. Las directrices voluntarias y un diálogo social asimétrico que deja a los gobiernos nacionales la posibilidad de no acatar los convenios y recomendaciones internacionales resultan en el evidente fracaso de su instrumentación. Esto nos lleva al punto más importante, claramente formulado por Faist (2009:24): ¿se puede acaso dar pie legal a derechos políticos transnacionales de sistemas multinivel?

Todas estas iniciativas juntas presentan una gran cantidad de trabajo y ejercicio discursivo; sin embargo, las opciones reales para la instrumentación de enfoques alternativos que contemplen la justicia social en términos de derechos y normas laborales deben analizarse con una perspectiva histórica y en el contexto de la actual economía política internacional. Con esto nos referimos a una "economía geopolítica" que retoma y transforma el papel del Estado-nación en el proceso de conformar la globalización en general y la migración global en particular (Samers, 1999).

En general, los discursos políticos sobre migración han expuesto una brecha entre argumentos y análisis basados en una "perspectiva de derechos" y aquéllos que toman una "perspectiva económica" (Solimano, 2001). Sin embargo, desde ambas perspectivas se espera que la libre migración tenga efectos positivos en el crecimiento económico de los países de origen y destino. La migración supondría, por consiguiente, una reducción en las desigualdades globales a largo plazo, mientras que, al mismo tiempo, se promoverían los derechos de ciudadanía transnacional. Esto es de hecho muy dudoso, tal y como argumenta Martin (2009) en relación con los enfoques críticos que examinan cuán difícil es proteger de manera efectiva a los migrantes transfronterizos poco calificados. Además, el aumento de la migración irregular y la economía informal dan lugar a disturbios políticos y conflictos sociales, como el racismo y la xenofobia.

La reducción en los salarios producida por la migración irregular y el deterioro de las condiciones de trabajo exige un análisis multifacético de las consecuencias de la migración internacional. En el contexto del 
TLCAN, la creciente desigualdad salarial en Estados Unidos, las casi tres décadas de recortes salariales (Peterson, 1994) y el deterioro en las diferencias salariales de mano de obra no especializada se atribuyen a los efectos combinados de la migración y el libre comercio (Borjas, 1999; Solimano, 2001). Además, como lo demuestra Solimano (2001), estudios fundamentados sobre migración internacional muestran una correlación positiva entre el libre comercio y el crecimiento de la migración internacional, lo opuesto a teorías económicas sobre migración y comercio que, como el modelo de Mundell, predicen una caída en la migración dentro del contexto del libre comercio y la movilidad del capital. Esto se relaciona con debates actuales sobre el efecto depresivo que el comercio internacional ha tenido sobre las normas laborales, especialmente para los trabajadores poco calificados (Izzo Arestoff et al., 2007).

Finalmente, la tendencia a ver la migración como un instrumento eficaz para el desarrollo ha sido cuestionado por la perspectiva sureña (Castles y Delgado Wise, 2007). Estas "paradojas de la migración" deben analizarse echando mano de los estudios críticos del desarrollo que apuntan hacia otras discrepancias entre las expectativas optimistas presentadas por las políticas de liberalización y desregularización de corte neoliberal, dando muestra de su actual y decepcionante impacto económico (Panchamukhi, 2000). ${ }^{6}$

\section{El atolladero de la instrumentación: actores y estrategias}

A raíz del fracaso para vincular las cláusulas sociales con los acuerdos comerciales de la OMC y los mecanismos de solución de controversias de 1996, la OIT se ha convertido en el principal institutor de la normatividad laboral. La promoción de los derechos de los trabajadores migrantes y la DWA contemplan varias estrategias que buscan una

6. Panchamukhi (2000:1) menciona cinco paradojas que han sido ignoradas por los estudios convencionales de desarrollo: a) la paradoja del crecimiento y la estabilidad, $b$ ) los efectos empobrecedores del ajuste estructural, $c$ ) la paradoja del aumento del desempleo en el marco de objetivos de pleno empleo, $d$ ) el crecimiento de las imperfecciones del mercado mientras se persigue una estrategia de creación de mercados perfectamente competitivos, y e) la paradoja del sistema de comercio de la OMC. 
eventual instrumentación: cabildeo a favor de la ratificación e instrumentación de la DWA, normas laborales fundamentales y convenios y recomendaciones migratorias específicos; promoción de normas laborales y cláusulas sociales a través de instrumentos relacionados con el comercio (por ejemplo, acuerdos comerciales unilaterales, bilaterales y regionales); y códigos voluntarios de conducta y RSC.

Sin embargo, dado el optimismo y laissez faire que impera en el escenario global, la OIT ha tenido serias dificultades en la promoción y establecimiento de cláusulas sociales y estándares laborales como normas efectivas en el comercio internacional (Malmberg y David, 1998). El poder que tiene la OMC para establecer las normas comerciales y el concomitante consenso político internacional en apoyo a una mayor liberalización del comercio en el ámbito de los servicios, respaldado por el Acuerdo General sobre el Comercio de Servicios (AGCS), no ha sido acompañado por una liberalización paralela de los regímenes de migración ni por la promoción de los derechos de los trabajadores migrantes o de la DWA; por el contrario, hemos visto un giro hacia la "securitización" de los regímenes de migración que se centra en la construcción de mecanismos de control fronterizo. Además, la evidencia ha confirmado que la regresión de los estándares laborales y de los derechos de los migrantes, tanto en países subdesarrollados como en países industrializados, especialmente en industrias exportadoras que requieren de trabajo intensivo poco calificado, están relacionadas con el comercio (OCDE, 2007; Arestoff-Izzo et al., 2007). Para explicar el poco efecto real de las normas laborales y la DWA, se incluyen las siguientes consideraciones: una plétora de documentos, informes y normas sin impacto real; falta de capacidad organizativa, legitimidad y poder político de los actores principales (la OIT, instituciones de la ONU, los sindicatos, las ONG) encargados de promover la agenda y obtener legitimidad; el hecho de que los gobiernos apoyan el trabajo decente de manera oficial pero no en la práctica; y el hecho de que los gobiernos no han adoptado una política coherente e integrada.

De hecho, existe una gran cantidad de reglas internacionales, normas e instrumentos regionales que adoptan una perspectiva migratoria general integral basada en los derechos humanos, así como enfoques 
centrados en derechos laborales y migración irregular. De instrumentarse, estas reglas protegerían a los migrantes de los peores tipos de explotación y de la trata de personas (convenios 97 y 143), garantizando el respeto de sus derechos a través de la Convención Internacional sobre la Protección de los Derechos de Todos los Trabajadores Migratorios y de sus Familiares de 1990. ${ }^{7}$ Sin embargo, estas declaraciones universales, convenios y recomendaciones tienen muy poco efecto si no están respaldados por sanciones eficaces. Algunos estudios sobre la articulación de un régimen internacional y su base normativa han señalado que incluso podría haber un efecto contraproducente dada la excesiva cantidad de normas e instrumentos, lo cual evidencia un grado de competencia organizativa dentro del sistema de la ONU (Ghosh, 1998; Hasenau, 1990). El ejemplo más notable de la falta de voluntad política para proteger los derechos de los migrantes es el hecho de que el Convenio sobre los Trabajadores Migrantes se hubiera iniciado en 1980, aprobado en 1990, comenzado su ratificación en 1998 y entrado en vigor en 2003, después de treinta años. La mayor parte de los países que lo han ratificado son países de origen, mientras que la mayor parte de los países receptores siguen sin hacerlo.

En lo que se refiere a los problemas de capacidad organizativa y legitimidad, la OIT ha sido criticada por largo tiempo dados sus vínculos con la hegemonía estadounidense y su tendencia a reprimir instancias de derechos laborales más progresistas (Vosko, 2002; Cox, 1977). Otro problema es su actitud inflexible y su falta de atención al contexto local y cultural, que a menudo conduce al fracaso en la instrumentación. Esto se refiere a la imposición de reglamentos y directrices laborales de corte estadounidense — un aspecto ya discutido por Piore (2010) —, o lo que se ve como efecto restrictivo de la interpretación de la OIT con respecto a la migración temporal como trabajo forzoso (Rogaly, 2008). La DWA es, sin embargo y por el momento, la única plataforma global que podría habilitar una instrumentación ambiciosa de los derechos de los trabajadores más marginados y desafiar así la hegemonía existente

7. Que tardó doce años en ser aprobada y más de una década en ser ratificada por el número de países necesario para entrar en vigor. 
con un régimen de gobernabilidad global que se apartase del consenso de Washington y la doctrina neoliberal (por ejemplo, Vosko, 2002).

La OIT ha, de hecho, ha mostrado creciente apertura y capacidad organizativa (Vosko, 2002:20), sobre todo después de que la UE y la Organización para la Cooperación y el Desarrollo Económico (OCDE) apoyaron la DWA; sin embargo, su inclusión discursiva no ha sido acompañada por prácticas de instrumentación decisiva a nivel gubernamental y transnacional. Expertos de la OIT han estado trabajando en la difusión de normas laborales internacionales en distintos países a través de los Programas Piloto de Trabajo Decente, pero una crítica reciente pide "un enfoque mucho más proactivo" (OIT, 2005). En su lugar, hemos visto algunas iniciativas para incluir normas laborales en los acuerdos comerciales regionales, unilaterales y bilaterales, así como una proliferación de iniciativas voluntarias para RSC bajo la iniciativa del Pacto Mundial de la ONU.

\section{Comercio y normas laborales básicas: UE, OCDE y TLCAN}

La UE y sus Estados miembros son los actores más importantes en la creación del régimen económico global dentro de un marco multilateral. Aunque la UE no es representada como un actor único ante el BM, el FMI y el sistema de la ONU, se ha convertido en un miembro de la OMC por derecho propio y ha otorgado cauteloso apoyo a diversas iniciativas globales para reforzar la dimensión social de la globalización y abordar cuestiones de justicia social: ha apoyado la revaluación y transnacionalización de la dimensión social de la globalización y del DWA. Por ejemplo, en 2001, la Comisión Europea (CE) indicó su apoyo a la promoción de normas laborales básicas y acciones políticas destinadas a reforzar su aplicación eficaz. Éstas incluyen mayor discusión dentro del marco de la OIT y la inclusión de estos temas en el discurso de desarrollo global; apoyo para la asistencia técnica de la OIT; inclusión de normas laborales en el Sistema Generalizado de Preferencias (SGP), las relaciones bilaterales y los acuerdos comerciales; responsabilidad corporativa, etiquetado social y códigos de conducta. Sin embargo, rechazó un enfoque basado en sanciones a la política comercial (CEC, 2001). En 2004, 
la Comisión respondió al informe WCSDG admitiendo el lado negativo de la globalización y la necesidad de promover la dimensión social de la globalización en el contexto europeo y mundial. En su comunicación (CEC, 2004), hizo hincapié en los aspectos sociales de la estrategia de Lisboa, la importancia del diálogo social, los Fondos Estructurales y el Fondo Social Europeo para amortiguar las consecuencias de la rápida reestructuración y para promover el capital humano y la "empleabilidad" en los nuevos Estados miembros (la antigua CEE). Sin embargo, la importancia del modelo social europeo, instrumentos políticos y métodos a favor de los aspectos sociales de la europeización no se toman enfáticamente en cuenta al abordar a otros países en transición y "terceros países", los cuales habían de recibir el apoyo de la nueva Política Europea de Vecindad o la política de desarrollo general basada en los ODM, los derechos humanos y la democratización. En todos estos comunicados, el principal objetivo e instrumento en la promoción de la dimensión social ha continuado siendo el libre comercio en conjunto con acuerdos bilaterales, la responsabilidad corporativa y las iniciativas sociales privadas. Los problemas relativos a los efectos sociales de la globalización habrían de abordarse a través de iniciativas de investigación, y la migración sólo ha sido contemplada como un paréntesis en los foros multilaterales.

Aunque la Confederación Europea de Sindicatos (CES) ha pedido de manera persistente que la UE tenga un compromiso más activo con la DWA, tal y como prometían las notas intercambiadas entre la CE y la OIT en 2001, el tema sólo se empezó a atender de manera seria en 2006. Parece que Bob Deacon (2005) predijo oportunamente un cambio en el discurso de la globalización hacia una consideración más seria de las políticas sociales universales. El comunicado de la CE (CEC, 2006), preparado conjuntamente por la direcciones generales de Empleo y Asuntos Sociales, Relaciones Exteriores, Desarrollo y Comercio, parece reflejar "el espíritu de los tiempos". Aquí, la Comisión enfatiza su fuerte influencia en la remodelación de la globalización a través de la inclusión de la DWA - como el noveno de los ODM - en todas sus políticas exteriores, incluyendo las políticas de ampliación, vecindad y cooperación en el desarrollo de la UE. Además, prometió promover una mejor gestión de la migración económica basándose en experiencias anteriores 
relativas a la promulgación de la libre circulación de trabajadores, sus derechos e integración dentro de la UE.

La UE ha ejercido un poder considerable y ha dado lugar a cambios en la OCDE hacia la DWA y nuevas políticas sociales y laborales, lo cual también implica una mayor participación de la Dirección de Empleo y Asuntos Sociales dentro de la estructura interna de la UE (Mahon, 2008). Esto es importante si tenemos en cuenta el hecho de que los países de la OCDE han firmado 176 acuerdos bilaterales de migración con diversos países como una forma de gestionar los flujos migratorios (OIT, 2010:200). La OIT (2010) sostiene que su Recomendación No 86 y su anexo, incluyendo un acuerdo sobre los trabajadores migrantes, que contiene cláusulas sobre condiciones de vida, trabajo y seguridad social, han sido ampliamente utilizados por muchos Estados. Sin embargo, la lista de naciones mencionadas no es ni larga ni significativa.

Por lo tanto, a pesar de las consideraciones sociales, la DWA y la existencia de fuertes argumentos económicos, políticos, de derechos humanos y gobernabilidad en apoyo de la rigurosa aplicación de las normas laborales fundamentales del OIT, parece evidente (por ejemplo, Witte, 2008) que los instrumentos de comercio de la UE y Estados Unidos han tenido muy poco impacto, en particular el SPG de la UE, que se basa en incentivos con sanciones leves (especialmente en el caso de los países menos adelantados o PMA), a pesar de la existencia de un mecanismo de denuncia que permite a sindicatos y actores de la sociedad civil denunciar casos de violación al Comité de la SGP. Otros acuerdos comerciales bilaterales, como aquellos de asociación económica (AAE), se centran más en los derechos humanos que en las normas laborales fundamentales (Witte, 2008:35-6).

Por otra parte, y en lo que respecta a la dimensión interna del mercado común, actores de la sociedad civil, como EurActive, han criticado la falta de atención prestada al deterioro de las normas laborales en la UE y países candidatos (EurActiv, 2006). En su estudio sobre la economía informal en la región de Europa central y del este y la Mancomunidad de Estados Independientes (CEE/CIS), Bettina Musiolek (2002) señala que las políticas estatales de desregulación para atraer IED son los principales obstáculos para la promoción de la DWA. Recientemente, la rama 
regional de la CEE de la Confederación Internacional de Organizaciones Sindicales Libres (CIOSL) ha iniciado el proceso de inclusión para trabajadores en la economía informal; se reconoce que los obstáculos se encuentran en su propia debilidad organizativa, la enorme dependencia de los sectores privado y estatal de la economía informal, y la ambivalencia de los Estados miembros de la CEE cuando se trata de regularizar y formalizar la economía informal (Glovackas, 2005). Considerando los poderosos discursos políticos y movimientos nacionalistas en la CEE y su falta de experiencia, instituciones y capacidad administrativa para gestionar la migración con debida atención a los derechos humanos o para generar la interacción e integración de los inmigrantes en comunidades locales, los nuevos Estados miembros requieren de recursos económicos específicos y ayuda para desarrollar instrumentos políticos y una base normativa para el reconocimiento y protección de los derechos de los trabajadores migrantes, así como condiciones decentes de trabajo (incluso en el caso de aquéllos en la economía informal).

En realidad, la más reciente ampliación de 2006, en lo que respecta a prácticas judiciales de la UE en materia de derecho laboral y política social, tuvo un impacto negativo sobre los derechos laborales e implicó una respuesta de los Estados miembros a la competencia global relativa a la reducción de las normas de protección (Krebber, 2009). El reciente análisis del Enfoque Global a la Migración (CEC, 2008) y la aprobación simultánea de la Directiva en lo que se refiere al regreso de inmigrantes ilegales, apenas cambia la tendencia general a favorecer el crecimiento económico y la baja inflación. Aunque el tema de la migración se enmarca en términos de "colaboración y solidaridad", el enfoque político sobre la migración ilegal enfatiza el regreso efectivo y un control fronterizo orientado a la seguridad. Esta orientación restringe el desarrollo y la emulación de un régimen de movilidad y migración con derechos basado en el modelo social europeo. Al mismo tiempo, el bajo nivel de los salarios y la protección social en un sistema con nuevas formas de precarización e informalidad laboral permiten una reducción continua en los salarios y la remercantilización y segmentación vertical del trabajo.

La configuración del marco institucional para la libertad, seguridad y justicia de la UE ha reforzado un nuevo panorama de precarización e 
inseguridad marcado por un fundamentalismo mercantil. Por otra parte, el objetivo europeo de luchar contra la migración irregular a través de controles fronterizos más estrictos y políticas de vecindad y desarrollo puede ser visto como una estrategia regional de neoliberalización de la ciudadanía y una remercantilización del trabajo a través de la creación de migrantes "útiles" (Geddes, 2005:788); una fuerza de trabajo desechable en condiciones más estrictamente supervisadas que aquéllas de los sistemas de migrantes laborales temporales en la década de 1960 (Joppke, 2007). Por último, las recientes respuestas políticas a la crisis financiera mundial sólo han reforzado esta dinámica. Los trabajadores migrantes, independientemente de su estatus, parecen llevar la carga principal de la crisis (Plummer, 2010). La actual recesión económica y el aumento del desempleo también han llevado a movilizaciones populares en contra de los trabajadores migrantes en los primeros Estados miembros. La discriminación de los romaníes en toda la UE es quizás el ejemplo más elocuente de la ineficacia de los instrumentos de lucha contra la discriminación. Actualmente, el proyecto de la UE se encuentra fragmentado en muchas direcciones marcadas por el impacto del "capitalismo rápido" y una xenofobia espontánea que se traduce en visiones populistas y nacionalistas de una "Europa integral" (Holmes, 2000). En la actual coyuntura de la crisis financiera, es difícil evaluar el potencial real de la promoción de la DWA en la UE para evitar la depreciación de las normas laborales.

En lo que respecta a Estados Unidos, su SGP emplea un enfoque punitivo a la violación de los derechos del trabajo. Además, cualquiera puede presentar una demanda relacionada con la violación de los derechos laborales y así iniciar una revisión. En el caso del TLCAN, existe un amplio marco para la promoción de los derechos laborales y las normas de conformidad con base en el Acuerdo de Cooperación Laboral de América del Norte (ACLAN). Sin embargo, aunque el acuerdo implica objetivos mucho más ambiciosos que los convenios fundamentales de la OIT, las estrictas medidas punitivas se aplican sólo en casos de trabajo infantil, condiciones mínimas de trabajo y riesgos en seguridad y salud ocupacional. También se exige un procedimiento de queja bastante complicado que puede ser presentado por los sindicatos y la sociedad civil ante las oficinas nacionales administrativas para su 
posterior examen. Las evaluaciones del ACLAN y sus repercusiones han sido en su mayoría negativas. El informe de la Federación Internacional de Derechos Humanos (FIDH) sobre el impacto de los derechos humanos y laborales del TLCAN en México muestra la inutilidad de todos los instrumentos jurídicos regionales, nacionales e internacionales para la protección de los derechos humanos y laborales en México en general, $y$ en las industrias de maquila en particular (FIDH, 2006). El informe concluye que, hasta el momento, las asimetrías regionales han favorecido a la economía estadounidense, pero la crisis financiera y su impacto en Estados Unidos demuestran que el juego no termina en México y tampoco afecta meramente a los trabajadores migrantes. La nueva interconexión regional y global dentro del TLCAN ha creado profundos desequilibrios en la economía estadounidense al canalizar y reforzar la desigualdad y la pobreza.

El caso de México demuestra la necesidad de análisis claros y la identificación de actores responsables, marcos institucionales y la validez de los mecanismos de instrumentación, ya que ni los gobiernos involucrados ni los actores regionales o mundiales han tenido la capacidad o disposición de instrumentar los acuerdos y disposiciones ya existentes sobre derechos humanos y laborales. Esto muestra, como argumenta Witte (2008:50), una dudosa incorporación de los derechos laborales a acuerdos comerciales que están en sintonía con agendas de política exterior. Otros factores importantes que deben ayudar en la instrumentación de normas laborales son las políticas nacionales, los sindicatos fuertes y una sociedad civil que ejerza presión sobre los gobiernos. Esto es de particular importancia dada la postura tomada por los empleadores, incluyendo su presunto apoyo a los derechos humanos y las normas laborales en términos de RSC.

\section{La RSC y el Pacto Mundial: ¿un dilema de negocios?}

Las organizaciones de empleadores son interlocutores sociales importantes e influyentes en los procedimientos tripartitas de la OIT. La Organización Internacional de Empleadores (OIE) y las empresas europeas (la ex UNICE) han apoyado la DWA y participado en la formulación del Marco 
Multilateral de la OIT para las Migraciones Laborales (OIT, 2010:203). Sin embargo, dentro del diálogo social, los empleadores han interpretado la DWA en términos de normas laborales mínimas, haciendo caso omiso de las reclamaciones más ambiciosas de la OIT para generar protección social universal. En el caso del diálogo sobre migración, su principal interés ha sido influir en las consultas de la OMC sobre la gestión global de movimientos transfronterizos de profesionales. En el contexto de un clima internacional de negocios amistoso y las aspiraciones de globalización de los gobiernos, se ha hecho posible relajar la DWA y subordinar su realización a consideraciones contextuales y de eficiencia. Al mismo tiempo, la incapacidad de los Estados y actores internacionales para negociar un marco normativo vinculante para empresas transnacionales o atender demandas públicas a favor de prácticas empresariales socialmente responsables ha generado diversas iniciativas de mercado para el desarrollo de códigos corporativos voluntarios (Witte, 2008:55). Durante las últimas dos décadas hemos visto una explosión de diversos códigos y normas, así como de nuevas formas de establecer códigos a través de empresas, ONG, académicos y alianzas públicas y privadas. En lo que se refiere al número de códigos y normas que se ocupan de disposiciones concernientes a los derechos laborales, Witte (2008) menciona los reportes de la OCDE (2000) y la OIT (1999) que listan, respectivamente, 153 y 268 códigos de esta índole. Los códigos y las normas son en su mayoría creadas por las empresas y asociaciones empresariales, pero ha habido una tendencia a establecer alianzas entre múltiples interesados con la participación de las empresas, ONG, sindicatos, organizaciones internacionales y gobiernos que, por un lado, estipulan códigos y normas y, por el otro, supervisan su cumplimiento. Mientras que la mayoría de estos códigos rara vez se extienden más allá de las normas laborales básicas utilizadas por los diversos interesados, estas alianzas tienen un contenido más cabal e incluyen salarios y horas de trabajo justos además de referirse a los convenios y recomendaciones de la OIT (Witte, 2008:62-3).

La participación de los actores de la sociedad civil y gobiernos con voluntad ha demostrado ser vital para los registros de instrumentación y se han desarrollado muchos modelos diferentes para medir la RSC. El más prominente es el Pacto Mundial, una iniciativa en la que participan 
7700 empresas, la ONU, varios gobiernos, y la sociedad civil y laboral. El Pacto Mundial declara como sus objetivos la promoción de los derechos humanos (DUDH) y los derechos laborales (la Declaración de la OIT relativa a los principios fundamentales y derechos en el trabajo). Un socio interesante es The Human Rights and Business Dilemma Forum (Foro del Dilema en Derechos Humanos y Negocios), impulsado por Maplecroft, una empresa de lucro orientada al análisis de riesgo. El Foro presenta excelentes informes con detallados registros sobre violaciones de derechos humanos y laborales en diversos contextos. También presenta diferentes estudios de casos en que los riesgos de las empresas transnacionales se convierten en cómplices de dichas violaciones cuando se trata de trabajadores migrantes, ya que hay una ausencia o falta de efectividad en legislación doméstica y leyes laborales para los migrantes, así como una falta de control en las empresas de reclutamiento. El dilema para las empresas responsables se formularía en los siguientes términos: ¿cómo puede una empresa garantizar condiciones de trabajo decente e igualdad de trato para los trabajadores migrantes dentro de sus propias operaciones - o aquéllas de sus socios comerciales y proveedores - cuando operan en una jurisdicción donde los trabajadores migrantes forman parte importante de la mano de obra y el gobierno no les proporciona una protección adecuada? (http://human-rights.unglobalcompact.org/dilemmas/migrant-workers/).

El dilema ético entre oportunidades de rentabilidad abiertas por incentivos gubernamentales a los inversores (por ejemplo, dispensación de impuestos, controles salariales y restricciones a las actividades sindicales), por un lado, y la RSC, por el otro, se ha traducido en feroces debates teóricos sobre la potencial rentabilidad de la RSC y su capacidad real para promover la DWA y los derechos de los trabajadores migrantes (Witte, 2008). Mientras que la participación de múltiples interesados y la movilización social han demostrado ser cruciales para la realización de algunos códigos privados y voluntarios de conducta en la cadena de suministro, la pregunta es, tal como apunta Witte (2008:70), si éstos son "una mera distracción y potencialmente una herramienta que desplazará la intervención de los gobiernos y sindicatos", limitando "la responsabilidad legal de marcas globales y [evitando] el daño a su reputación”. 
En cuanto a los efectos reales, hay investigaciones que dan prueba de avances en la mejora de las condiciones de trabajo y normas laborales, especialmente en los contratos a largo plazo en cadenas de proveedores. Sin embargo, estos mismos informes hacen hincapié en que los trabajadores más vulnerables (migrantes empleados por contratistas laborales o trabajadores en la economía informal) han permanecido sin protección (Barrientos, 2008; Barrientos, Dolan y Tallontire, 2003). Por lo tanto, es fundamental que nos hagamos nuevas preguntas con base en lo mencionado por Witte (2008:76): ¿ Pueden las normas voluntarias evolucionar a leyes? ¿Pueden los gobiernos desempeñar un papel en el monitoreo del cumplimiento de estas normas? ¿Pueden las iniciativas voluntarias ayudar a fortalecer la capacidad de los sistemas nacionales?

\section{Sindicatos, ONG y movimientos sociales}

Las prácticas de implementación de derechos humanos, la DWA y los derechos de los migrantes tienen dos rasgos en común: por un lado, la falta de instrumentación y, por otro, su potencial de movilización (Faist, 2009:27). El problema se relaciona con la estrategia transnacional y la capacidad organizativa real de los actores multilaterales no estatales: los sindicatos, las ONG internacionales, las comunidades académicas y la sociedad civil en general. ¿Pueden ellos generar una diferencia significativa?

Básicamente, se han seguido dos caminos: uno apunta hacia el empoderamiento del "precariado", el cual entendemos como una fuerza de trabajo desechable sin derechos básicos, sin seguridad; el otro se orienta hacia la gobernabilidad de la cadena de producción, donde el papel de los organismos multilaterales, empresas transnacionales y el Estado resulta el punto central. En el primer caso, ha habido una división entre los sindicatos y las ONG; los sindicatos han sido criticados por su carácter burocrático, su nacionalismo y la exclusión de aquéllos en las situaciones más precarias en términos de ciudadanía y nicho en el mercado laboral, mientras que su capacidad organizativa y democracia interna han sido elogiadas (Silverman, 2005; Eade y Leather, 2004). Sin embargo, la movilización de los sindicatos contra la criminalización de los inmigrantes ilegales en mítines a lo largo de Estados Unidos y varios países europeos apunta hacia un cambio en sus actitudes y prácticas. 
La DWA ha jugado un papel importante como plataforma común para la unificación y consolidación de la Confederación Sindical Internacional (CSI), establecida en 2006. La promoción de la DWA ha mejorado la capacidad organizativa de los sindicatos para actuar tanto a nivel local como global y desarrollar nuevas formas de movilización y alianzas con la sociedad civil (Schmidt, 2007). Además, los nuevos movimientos sociales laborales internacionales a favor de los derechos de los inmigrantes han proliferado a nivel local y transnacional, generando esperanzas en la creación de un movimiento de oposición mundial (Burawoy, 2010).

Las ONG han sido elogiadas por su organización flexible, pero se les ha criticado su falta de coordinación y un enfoque que busca la reducción de la pobreza haciendo caso omiso de las cuestiones laborales (Eade y Leather, 2004). ${ }^{8}$ El empleo y las condiciones laborales, sin embargo, han sido abordadas por la red de investigación WIEGO en el manual Mainstreaming Informal Employment and Gender in Poverty Reduction (Incorporando el empleo informal y el género en la reducción de la pobreza, Chen, Vanek y Carr, 2004). Otra iniciativa es la de la Plataforma para la Cooperación Internacional sobre Inmigrantes Indocumentados (PICUM, por sus siglas en inglés), una ONG paraguas situada en Bruselas. El informe Ten Ways to Protect Undocumented Migrant Workers (Diez maneras de proteger a trabajadores migratorios indocumentados, PICUM, 2005) pide la participación cívica y sindical en la promoción de derechos humanos y laborales para migrantes indocumentados y su potenciación a través de una reformulación de las políticas de integración de la UE y la Estrategia Europea de Inclusión Social. Recientemente, la DWA se convirtió en la principal plataforma de Solidar, una red europea de 52 ONG procedentes de 25 países que lucha por los derechos sociales, laborales y por los migrantes en Europa.

Por último y no de menos importancia, la DWA desempeñó un papel significativo en la movilización de los migrantes previa a la reunión de 2008 del Foro Mundial sobre Migración y Desarrollo (FMMD). El informe señala que un enfoque basado en los derechos a la migración no se ocupa únicamente de derechos afines a los migrantes y la migración, sino también de principios generales como el derecho al desarrollo

8. Para una crítica radical de la sociedad civil mundial, ver Waterman (2004). 
y la DWA. El objetivo de este enfoque es garantizar el desarrollo sustentable y prevenir la explotación de aquéllos que se desplazan a vivir y trabajar en el extranjero (MFA, 2009:17). Junto con la promoción de los derechos de los trabajadores migrantes, se ha reconocido la importancia de organizar e incluir a los propios migrantes en el debate sobre el desarrollo (Piper, 2009). De hecho, la apertura y la pluralidad de la red de la AGP, junto con una movilización transnacional basada en una perspectiva crítica sobre la globalización neoliberal, podría prevenir la necesidad de cooptar una tediosa labor preparatoria para revaluar el nexo entre migración y desarrollo, y así ayudar a frenar la actual ola de mercantilización y precarización del trabajo.

Sin embargo, con todo el entusiasmo generado por la movilización social, cabe un poco de prudencia:

el optimismo de hoy tiene que contrarrestarse con un pesimismo sin concesiones; no alarmismo sino un análisis cuidadoso y detallado de la manera en que el capitalismo combina la mercantilización de la naturaleza, el dinero y el trabajo y que, por lo tanto, destruye el piso mismo sobre el cual podría construirse un movimiento de oposición (Burawoy, 2010:312).

\section{¿Qué hay que hacer? Una reconsideración de la rendición de cuentas inclusiva}

Hemos visto que el problema de la instrumentación de la DWA ha sido reformulado en términos de gobernabilidad (es decir, los conjuntos formales e informales de instituciones y las políticas que establecen la interacción entre la sociedad y la economía), pero que carece de acción decidida por parte de los gobiernos. Por otra parte, hemos visto que actores poderosos como las empresas transnacionales, los Estados nacionales y los órganos regionales de gobierno han adoptado iniciativas de comercio justo pero han sido mucho menos entusiastas en la promoción de la DWA mediante marcos normativos con sanciones que promuevan los derechos de los trabajadores migrantes y aseguren la instrumentación de los derechos humanos y laborales. Muchos gobiernos apoyan formalmente el programa pero, como hemos visto, la responsabilidad de su instrumentación ha pasado al diálogo social abierto y se basa en 
una amplia movilización de la sociedad civil. En el contexto de la actual crisis financiera global es importante destacar el renovado entusiasmo gubernamental por el libre comercio y la austeridad macroeconómica, lo cual podría generar un nuevo ciclo de regresión en políticas sociales. Esta situación es precaria y es hora de que agentes de la sociedad civil en general adjudiquen nuevamente la responsabilidad a los gobiernos, órganos regionales, la OMC y las empresas transnacionales.

¿Cuál sería, entonces, un enfoque proactivo? El argumento básico de este trabajo establece que los gobiernos nacionales, los actores de mayor poder en la gobernabilidad global, y los actores regionales son los responsables de instrumentar los derechos humanos, laborales y migratorios en conjunto. Y mientras que los Estados siguen siendo responsables del cumplimiento de estos derechos en su territorio, independientemente de cuestiones de ciudadanía, los actores globales tienen que responsabilizarse por establecer una política que respete estos derechos universales. Con las nuevas constelaciones de poder en el FMI y la OMC, con la creciente prominencia de China y la India, es de suma importancia establecer la responsabilidad de los Estados ante las violaciones de los derechos humanos y laborales en sus territorios.

La UE y América tienen que reiterar su compromiso con las cláusulas sociales de la OIT y con un enfoque migratorio con derechos en las deliberaciones de la OMC. La OIT y la CSI deben participar como iguales en consultas sobre una gestión global migratoria que esté regulada y sea accesible a los empleadores.

Finalmente, la AGP, los sindicatos, activistas académicos, cuerpos de la ONU y los gobiernos interesados del GFMD deben participar en un proceso creativo que simplifique las demandas normativas y establezca un modelo eficiente para la institucionalización, legalización y codificación de un régimen de derechos que garantice un piso digno de protección social para todos. Ya es hora de que pasemos de las "pláticas decentes" a las "prácticas decentes". Tenemos que recuperar el enfoque de una globalización justa y un modelo de desarrollo que reconozca a la sociedad, revalúe la solidaridad transnacional en términos de políticas migratorias con que se reconozcan los derechos y capacidades humanas, y exija la responsabilidad y rendición de cuentas por parte de gobiernos y actores internacionales para promover la justicia social global. 


\section{REFERENCIAS}

ArendT, Hannah (1958), The Origins of Totalitarianism, New York, Meridian Books.

Arestoff-Izzo, Florence et al. (2007), The Use, Scope and Effectiveness of Labour and Social Provisions and Sustainable Development Aspects in Bilateral and Regional Free Trade Agreements, Contract VC/2007/0638, European Commission. Employment, Social Affairs and Equal Opportunities DG.

BARRIEnTOS, Stephanie (2008), "Contract Labour: The 'Achilles Heel' of Corporate Codes in Commercial Value Chains" en Development and Change, 39 (6), 977-990.

BARrientos, Stephanie, Catherine Dolan y Anne Tallontire (2003), "A Gendered Value Chain Approach to Codes of Conduct in African Horticulture" en World Development, 31 (9), 1511-1526.

BAUder, Harald (2006), Labor Movement: How Migration Regulates Labor, Oxford: Oxford University Press, Oxford, Oxford University Press.

BeITZ, Charles (2009), The Tdea of Human Rights, Oxford, Oxford University Press. BORJAS, George J. (1999), "Economic Research on the Determinants of Immigration: Lessons for the European Union”, Washington, World Bank, Technical Paper, núm. 438, septiembre.

Burawoy, Michael (2010), "From Polanyi to Pollyanna: The False Optimism of Global Labor Studies" en Global Labour Journal, 1 (2), 301-313.

Castles, Steven y Raúl Delgado Wise (eds.) (2007), Migration and Development. Perspectives from the South, Geneva, International Organization for Migration (IOM).

Cec (2001), Promoting Core Labour Standards and Improving Social Governance in the Context of Globalisation, Bruselas, COM 416 final.

(2004), The Social Dimension of Globalisation: The EU's Policy Contribution on Extending the Benefits to all, Bruselas, COM (2004) 383 final.

(2006), Promoting Decent Work for All. The EU Contribution to the Implementation of the Decent Work Agenda, Bruselas, COM (2006) 249 final/SEC (2006) 643.

(2008), A Common Immigration Policy for Europe: Principles, Action and Tools, Bruselas, COM (2008) 359 final.

CHEN, Martha Alter, Joann Vanek y Marilyn Carr (2004), Mainstreaming Informal Employment and Gender in Poverty Reduction, $\mathcal{A}$ Handbook for Policy-makers and Other Stakeholders, Londres, The Commonwealth Secretariat. 
Clarke, John N. (2004), "Conclusion: Dimensions and Processes of Global Governance”, en Clarke, John N. y Geoffrey R. Edwards (eds.), Global Governance in the Twenty-First Century, Houndmills, Palgrave MacMillan.

Clarke, John N. y Geoffrey R. Edwards (2004), "Introduction”, en John N. Clarke y Geoffrey R. Edwards (eds.), Global Governance in the Twenty-First Century, Houndmills, Basingstoke y Nueva York, Palgrave MacMillan.

Cox, Robert W. (1977), "Labour and Hegemony" en International Organization, 31 (1), 385-424.

DEACON, Bob (2005), "From 'Safety Nets' Back to 'Universal Social Provision': Is the Global Tide Turning?” en Global Social Policy, 5 (1), 19-28.

DORE, Ronald (2008), "Financialization of the global economy" en Industrial and Corporate Change, 17 (6), 1097-1112.

EADE, Deborah y Alan Leather (eds. 2004), Trade Unions and NGO Relations in Development and Social Justice, Development in Practice, 14 (1-2),5-285.

EURACTIV (2006), "Commmission to promote 'decent work' in the world", http://www.euractiv.com/en/socialeurope/commission-promote-decentwork-world/article-155553.

FAIRCLOUGH, Norman (1992), Critical Discourse Analysis, Londres, Longman. FAIST, Thomas (2009), “The Transnational Social Question. Social Rights and Citizenship in a Global Context" en International Sociology, 24 (1), 7-35.

Fidh (2006), Mexico: The North American Free Trade Agreement (NAFTA): Effects on Human Rights, Violations of Labour Rights, núm. 448/2, International Federation for Human Rights, http://www.unhcr.org/refworld/ docid/46f146860.html.

FRADE, Carlos e Isabelle Darmon (2005), "New modes of business organization and precarious employment: towards the recommodification of labour", Journal of European Social Policy, 15 (2), 107-21.

Gсім (2005), Migration in an Interconnected World: New Directions for Actions, Ginebra, Global Commission on International Migration.

GEDDES, Andrew (2005), “Europe's Border Relationships and International Migration Relations", Journal of Common Market Studies, 43 (4), 787-806.

Gentile, Antonina y Sidney Tarrow (2009), "Charles Tilly, Globalization, and Labor's Citizen Rights”, European Political Science Review, 1 (3), 465-493.

GHosH, Bimal (1998), Huddled Masses and Uncertain Shores. Insights into Irregular Migration, La Haya, Martinus Nijhoff Publishers.

GILL, Stephen (2005), "New Constitutionalism, Democratisation and Global Political Economy", en Rorden Wilkinson (ed.), The Global Governance Reader, Londres, Routledge. 
Glovackas, Sergejus (2005), The Informal Economy in Central and Eastern Europe, Ginebra, Global Labour Institute, http://www.globallabour.info/ en/2007/09/the_informal_economy_in_centra_1.html.

HARVEY, David (2005), A Brief History of Neoliberalism, Oxford, Oxford University Press.

HasenaU, M. (1990), "Setting Norms in the United Nations Systems: The Draft Convention on the Protection of the Rights of All Migrants and Their Families in Relation to ILO Standards on Migrant Workers" en International Migration, 28 (2), 133-158.

HerTEL, Shareen (2009), "Human Rights and the Global Economy: Bringing Labor Rights Back In" en Maryland Journal of International Law, 24, 240-252.

Holmes, D.A. (2000), Integral Europe. Fast-capitalism, Multiculturalism, Neofascism, Princeton y Oxford, Princeton University Press.

ILo (1999), Decent Work: Report of the Director-General to the 87th Session of the International Labour Conference, Ginebra, ILO.

(2001), Reducing the Decent Work Deficit. A Global Challenge. Report of the Director General to the 89th Session of the International Labour Conference, Ginebra, ILO.

(2005), Decent Work and a Fair Globalization: National Policy Responses, Ginebra, ILO.

(2010), International Labour Migration: $\mathcal{A}$ Rights-Based Approach, Ginebra, ILO.

JoneS, Charles (2010), "Human Rights and Moral Cosmopolitanism” en Critical Review of International Social and Political Philosophy, 13 (1), 115-135.

JOPPKE, Christian (2007), “Transformation of Immigrant Integration: Civic Integration and Antidiscrimination in the Netherlands, France, and Germany" en World Politics, 59 (2), 243-273.

Krause, Monika (2008), "Undocumented Migrants: An Arendtian Perspective" en European Journal of Political Theory, 7(3), 331-348.

KrebBer, Sebastian (2009), "Status and Potential of the Regulation of Labour and Employment Law at the Europen Level" en Comparative Labor Law and Policy Journal, 30, 875-903.

LAFONT, Cristina (2010), "Accountability and Global Governance: Challenging the State-centric Conception of Human Rights" en Ethics and Global Politics, 3 (3), 193-215.

LIKIC-BRBORIC, Branka (2003), Democratic Governance in the Transition from Yugoslav Self-Management to a Market Economy. The Case of the 
Slovenian Privatization Debates 1990-1992, Uppsala Studies in Economic History, Uppsala, Uppsala University. (2007), "Globalisation, EU Enlargement and New Migratory Landscapes: The Challenge of the Informal Economy and Contingencies for 'Decent Work"', en Erik Berggren, B. Likic-Brboric, G. Toksöz y N. Trimikliniotis (eds.), Irregular Migration, Informal Labour and Community in Europe, Maastricht, Shaker Publishing.

Luxemburg, Rosa (1951/1963), The Accumulation of Capital, Londres, Routledge y Kegan Paul Ltd.

MAHON, Rianne (2008), "Babies and Bosses: Gendering the OECD's Social Policy Discourse", en Rianne Mahon y Stephen McBride (eds.), The OECD and Transnational Governance, Vancouver, UBC Press

Malmberg, Jonas y David Johnsson (1998), Social Clauses and Other Means to promote Fair Labour Standards in International Fora, Arbetslivsrapport, núm. 25, Stockholm, Arbetslivsinstitutet.

Martin, Philip y Manolo Abella (2009), "Migration and Development: The Elusive Link at the GFMD”, International Migration Review, 43 (2), 431-439.

Mfa (2009), Mobilizing Migrant Community and Civil Society Voices for the Second Global Forum on Migration and Development (GFMD): The Migrant Forum in Asia Experience, Migrant Forum in Asia, http://www.mfasia.org/ pga/resources/GFMD2008Report.pdf.

MUNCK, Ronaldo (2007), Globalisation and Contestation: the New Great Counter-movement, Nueva York, Routledge.

MusioleK, Betina (2002), Decent Work in the Informal Sector CEE/CIS Region, núm. 7, Ginebra, International Labour Office.

OECD (2007), OECD Employment Outlook 2007, París, OECD.

Orт (2003), Trabajo decente y la economía informal. Conferencia Internacional del Trabajo, 90a Reunión, 2002, Ginebra: OIT.

Overbeek, Henk (2003), “Transnational Political Economy and the Politics of European (Un)employment” en Overbeek, Henk (ed.), The Political Economy of European Employment. European Integration and Transnationalization of the (Un)employment Question, Londres y Nueva York, Routledge Taylor \& Francis Group.

PANCHAMukHi, V. R. (2000), "Five Recent Paradoxes and Anomalies of Economics" en Asia-Pacific Development Journal, 7 (2 ), 1-31.

PAPADOPOUlOS, Theo (2005), “The Recommodification of European Labour: Theoretical and Empirical Explorations", The University of Bath, The 
European Research Institute (ERI), http://www.bath.ac.uk/eri/ERI-workingpapers/ERI-working-paper-05-03-final.pdf.

Peterson, Wallace C. (1994), Silent Depression. Twenty-five Years of Wage Squeeze and Middle-Class Decline, Nueva York y Londres, W. W. Norton \& Company.

Picum (2005), Ten Ways to Protect Undocumented Migrant Workers, Brussels, PICUM (Platform for International Cooperation on Undocumented Migrants).

PIORE, J. Michael (2009), "Second Thoughts: On Economics, Sociology, Neoliberalism, Polanyi's Double Movement and Intellectual Vacuums" en SASE Annual Meeting 2008, San José, Costa Rica, Socio-Economic Review, 7(1), 161-175.

(2010), "Flexible Bureaucracies in Labour Market Regulations" en The Idea of Labour Law, St. Catherine College, Cambridge, Reino Unido, abril 8-9, 2010.

Piper, Nicola (2009), Migration and Social Development: Organizational and Political Dimensions, núm. 39, Geneva, UNRISD.

Plummer, Robert (2010), "Migrants Feel Recession Aftermath" BBC News.

PolANYI, Karl (2001 (1944)), The Great Transformation. The Political and Economic Origins of Our Time, Boston MA, Beacon Press.

RogALY, Ben (2008), "Migrant Workers in the ILO's Global Alliance Against Forced Labour Report: a critical appraisal” en Third World Quarterly, 29 (7), 1431-47.

SAMERS, Michael (1999), “'Globalization', the geopolitical economy of migration and the 'spatial vent"' en Review of International Political Economy, 6 (2), 166-199.

SchieruP, Carl-Ulrik, Peo Hansen y Stephen Castles (2006), Migration, Citizenship and the European Welfare State. A European Dilemma, Oxford, Oxford University Press.

ScHmidT, Verena (ed.) (2007), Trade Union Responses to Globalization, Geneva, ILO.

Silverman, Nicole Andrea (2005), Deserving Decent Work: the Complications of Organizing Trregular Workers Without Legal Rights, COMPAS Working Papers, núm. 21, Oxford, University of Oxford.

SLAVNIC, Zoran (2010), "Political Economy of Informalization" en European Societies, 12 (1), 3-23.

Solimano, Andrés (2001), "Global Migration and the Global Economic Order: An Overview” en Policy Research Working Paper, núm. 2720, Washington D. C., The World Bank. 
SOYSAL, Yasemin (1994), The Limits of Citizenship: Migrants and Postnational Membership in Europe, Chicago, University of Chicago Press.

ThÉRIEN, Jean-Philippe (2005), "Beyond the North-South Divide: The Two Tales of World Poverty", en Rorden Wilkinson (ed.), The Global Governance Reader, London, Routledge, Taylor \& Francis Group.

WAITE, Luise (2009), "A Place and Space for a Critical Geography of Precarity?” en Geography Compass, 3 (1), 412-433.

WATERMAN, Peter (2004), “Trade Unions, NGOs and Global Social Justice: Another Tale to Tell”, http://www.risq.org/article383.html.

WCsDg (2004), A Fair Globalization:Creating Opportunities for All, Geneva, ILO. Vetterlein, Antje (2007), "Economic Growth, Poverty Reduction, and the Role of Social Policies: The Evolution of the World Bank's Social Development Approach" en Global Governance, 13 (4), 513-533.

Witte, Jan Martin (2008), Realising Core Labour Standards. The potential and limits of voluntary codes and social clauses. A review of literature, Global Public Policy Institute, German Federal Ministry for (BMZ), Economic Cooperation and Development.

Woolfson, Charles y Branka Likic-Brboric (2008), "Migrants in the Unequal Burdening of 'Toxic' Risk: Towards a New Global Governance Regime” en Debate: Journal of Contemporary Central and Eastern Europe, 16 (3), 291-308.

Vosko, Leah F. (2002), “'Decent Work' : The Shifting Role of the ILO and the Struggle for Global Social Justice”, Global Social Justice, 2 (1), 19-46. 
